\title{
Cultural Reflections on the Inheritance and Development of Local Operas in China - A Case Study of Ancient Houhe Opera in the Southeast of Chongqing
}

\author{
Juan Xue ${ }^{1, a}$ \\ ${ }^{1}$ The College of Literature and Journalism of Sichuan University, Chengdu, Sichuan Province, \\ China
}

a763457921@qq.com

Key words: local operas in China, nation, region, culture, heritage

\begin{abstract}
The inheritance and development of Chinese local operas embody important historical and cultural values, as well as crucial practical significance. Due to various kinds of reasons, a considerable number of local operas have bordered on the extinction. Under that situation, measures from four aspects can be used to effectively promote the inheritance and development of traditional Chinese local operas. The government should play the leading role, providing economic supports and policy stimulus. Schools need to carry out related teaching and researching activities, and advocate Houhe Opera in campus. Local opera artists ought to play their principal roles, trying to create more play scripts with local characteristics. The market can also promote and improve relevant industries.
\end{abstract}

\section{Introduction}

China is rich in opera cultural resources. After a thousand years of development and evolution, local operas have become a kind of artistic form with unique national features. According to statistics, in early 80s, the total number of opera genres in China was 317. [1] In the last three decades, with the development of economy and culture, dramatic arts suffered great impacts. Some local dramas are nearly lost or totally disappear. As an important part of traditional arts, the preservation, inheritance and development of local operas are important to carrying forward our traditional culture. Therefore, this paper discusses the inheritance and development methods of Chinese local operas with Houhe Opera as the example, hoping to make a contribution to the preservation of traditional culture. Houhe Opera is a kind of local opera in Zhuoshui area, southeast of Chongqing. Now it is nearly lost.

\section{Houhe Opera and Its Heritage Value}

Houhe Opera in Zhuoshui was originated in the ancient town of Houhe, Zhuoshui in Wuling mountainous area in the reign of Emperor Tongzhi during Qing dynasty. It has a history of over one hundred and forty years. Houhe Opera integrates features of Hanchu Opera, Sichuan Opera and South Play in Hubei, as well as ethnic, custom and regional cultural elements in Wuling mountainous area. The opera is consist of singing, speaking, acting and acrobatic fighting; it embodies the artistic qualities of music, dancing, singing, movements, fine arts, martial arts and acrobatics. [2] The vocal music, artistic languages and musical images of Houhe Opera are different 
from other local operas, and reflect the humanity environment of the minority area in southeast of Chongqing.

For more than a hundred years, Houhe Opera has not only enriched the entertainment life of residents, but also affected their moral and cultural values from generation to generation. From the view of practical value, Houhe Opera is the cultural name card of the southeast of Chongqing. In this area, it is one of the four most important attractions for tourists in these ancient towns with national features. Houhe Opera, Wulong Impression Show, Xiushan Festive Lantern and Manghao Trumpet are unique art forms in the ethnic area, and are extremely important to the development of regional economy. What's more, the performance methods and content layouts of Houhe Opera are more flexible. Thus, the drama can be used as an important way of cultural propaganda in promoting the spirit of the times, and the construction of a harmonious society.

As a kind of folk culture in the southeast of Chongqing, Houhe Opera has important historical and cultural values, as well as social significance. But now it is on the verge of extinction. How to inherit this cultural legacy, and find the right way to develop Chinese local operas? These are urgent problems needed to be dealt with by literary and art workers.

\section{Present Situation of Houhe Opera and Reasons for its Near Extinction}

Under the impact of multi-culture, many kinds of local operas, including Houhe Opera, are now bordered on the extinction. A careful analysis on related reasons is the key to finding out methods for developing and inheriting the ancient Houhe Drama. According to the field survey, the current situation of Houhe Opera and related reasons are found as follows.

Lack of successors. Now in Zhuoshui, there are only twelve performers of Houhe Opera, and the aging trend is getting serious. Most of these actors are seventy years old. The oldest actor is now in eighties, while the youngest is in thirties. The age gap in talent pool is the biggest problem in the inheritance of Houhe Opera.

Loss of audience. As the pace of life accelerates, traditional dramas with meticulous work and slow rhythm are now difficult to attract quantity of viewers from the new generation. Under the impact of multiculturalism, young people prefer entertainment forms which can shock their sensory organs, like televisions and network. They do not have aesthetic feelings and enough patience in watching the traditional Houhe Opera, which is based on traditional cultures and aims to mould people's temperament.

Scripts are in small quantity and short of originality. In 50s and 60s of last century, Houhe Opera was used to perform opera highlights like Mu Ke Zhai, Sister-in-Law, Nine Clothes and Distributing Grain at Chenchow. These scripts were lack of regional characteristics. In 70s and 80s, actors of Houhe Opera followed the trend of the times, and created original scripts like Spring in Apeng River and Family Separation. They wrote and played these operas by themselves. These plays were close to the life of people in the southeast of Chongqing, and were relatively popular. But since then, no good scripts with originality and epoch topics were created.

Imperfect protection measures of the local cultural sectors. The local government and relevant departments have noticed the importance of Houhe Opera and implemented some remedial measures, such as listed Houhe Opera into intangible cultural heritage of district, and the second 
batch of intangible cultural heritage of Chongqing in 2009. But these measures do not achieve good results.

The new times and the old traditions, the quick of modern times and the slow of Houhe Opera development, are sharp contradictions which threaten the existence and development of Houhe Opera in the civilization river.

\section{Reflections and Suggestions on the Inheritance and Development of Houhe Opera}

The important cultural values of Houhe Opera, together with the serious situation faced by it, decide that effective protection measures with both macro strategy and regional characteristics must be taken appropriately and timely. Only in that way, can we guarantee the healthy development of Houhe Opera. Concretely speaking, the inheritance and development of the traditional Houhe Opera can be realized from the following four aspects.

The government should play the leading role, providing economic supports and policy stimulus. The endangered status of Houhe Opera decides that the government and relevant departments must take the main responsibility. They should earnestly perform their duties, and properly preserve the important cultural heritage. Specifically measures include the following:

Paying attention to the existing excellent performers, and training successors of Houhe Opera. There's no specialized training school for Houhe Opera performers. The inheritance of Houhe Opera relies on master and apprentice mentoring system. But the existing performers are unable to take the responsibility of cultivating successors. Theatrical performances are low-income activities; drama lovers are forced to find another career. In view of this situation, the government should provide strong backing to the inheritance of cultures and arts. Related departments need to pay attention to existing excellent performers of Houhe Opera, and ensure "each generation produces its own outstanding talents”. The successors of Houhe Opera should be selected and identified.

Establishing complete troupe organization. Perfect troupe organization is important to the inheritance and development of Houhe Opera. The mechanism includes recruiting students extensively, training and selecting talents, making long-term and feasible training plans to provide respects and material securities to successors of cultures and arts, collecting traditional scripts and outstanding modern scripts, arranging fixed performance sites, and providing financial supports in purchasing musical instruments, costumes and props.

Building museums to preserve the intangible cultural heritage. Houhe Opera is the epitome of cultures and customs in the Southeast of Chongqing. It makes an important contribution to the formation of the unique Chinese cultural landscape and traditional culture carriers. From the perspective of art development, natural selection is an inevitable trend, and the old things are always superseded by the new. During the process of multi-media entertainment, some traditional operas, such as Houhe Opera, lose their old audiences. The government and relevant departments can build cultural museums to protect these forms of operas, and explore their values as cultural carriers and historical witnesses.

Schools need to promote related teaching and researching activities. Houhe Opera is a form of entertainment. The interests and supports of audiences are essential to the development and propagation of it. Nowadays, the newest groups of youngsters do not like traditional Chinese operas. Thus, it is necessary for schools to lead traditional cultures to them, and help them to understand 
and inherit the cultures created by their own ancestors. Cultivating people's culture identities, and deepening their affections to traditional cultures, are measures to cultivate successors and improve the living environment of Houhe Opera in the long run. Schools can organize lectures to publicize drama knowledge, and arrange different kinds of performances according to the age and interest of students. Young audience can be cultivated through these methods.

In addition, in order to further promote the inheritance and development of Houhe Opera, students should be helped to learn and inherit the drama on the basis of their understandings and appreciations. Appropriate policies, such as establishing interest and specialty training classes and setting up students' performance groups, should be used to encourage students to learn traditional drama.

At last, enough attentions should be paid in studying related drama theory. The occurrence, development and future trend of Houhe Opera should be studied deeply from the perspective of local dramas and local cultures. Experts and scholars should carry out cultural rescue projects to explore and preserve the cultural factors of local dramas.

Local opera artists ought to play their principal roles, trying to create more play scripts with local characteristics. As the important main part of Houhe Opera inheritance, performers play important roles in the inheritance and development of this traditional opera. Houhe Opera needs innovation on the basis of heritance. Trying to create outstanding operas with the unique characteristics and advantages is the key responsibility burdened by artists.

Increasing innovative and original scripts. Through the study of Houhe Opera scripts, it is found that these scripts are in low quality and lack of originality. These are major obstacles in the path of developing Houhe Opera. At the beginning of reform and opening up, actors of Houhe Opera created original scripts like Spring in Apeng River and Family Separation. These original plays followed the trend of times, and were close to the life of people in the southeast of Chongqing. They got some appraises, but they did not get promotion as Top-grade Drama.

In recent years, the government encourages the implementation of excellent stage art works. Innovations in drama receive attentions again. In the year of 2002-2003, six outstanding local operas with originality and unique cultural characteristics were selected as the Ten National Excellent Stage Art Projects. The National Excellent Stage Art Projects attach great importance to originality. "The Excellent Projects support and encourage original works”; "advocating originality means encouraging artists to express their own perceptions and cognition"; "the Excellent Projects applies preferential policy to encourage and support the original spirit of artists.”[3]

Innovation is the spirit of a nation's progress. In the new century, dramas artists need to create innovate and excellent works to achieve the historical transition and to further realize the cultural and artistic values of operas. Local drama artists should innovate and create outstanding works based on local characteristics. It is the way for local operas to realize revitalization.

Further emphasizing the regional and national characteristics of Houhe Opera. As the local opera in the southeast of Chongqing, Houhe Opera adopts the singing and performance methods of South Play in Hubei. In addition, it integrates its own dancing and music styles, dialect characteristics and cultural customs. In this way, Houhe Opera becomes a kind of local opera with unique local style. However, in the aspects of clothing and props, Houhe Opera still follows the clothing style of South Play. In terms of the art form, which belongs to the regional belongs to the world. Cultures with more local characteristics usually have more conservation and heritage values. 
Zhuoshui Area located in the southeast of Chongqing. This place gathers people from Tujia, Miao and Han nationalities. Houhe Opera should learn from these nationality cultures, and gradually become a symbol of national culture. For example, artists can use Xilan Kapu, the local brocade of Tujia people into drama costumes; apply the traditional Nuo Drama and Festival Lantern Culture into the performance. These cultural elements can provide Houhe Opera with a bigger stage and cultural field. Thus, regional and national characteristics of Houhe Opera can be further enhanced, and the operas can become more appealing.

Market regulation. Merchants can promote and improve relevant industries. In the modern market economy, marketization is the only way to the develop Houhe Opera. If there's no market, no drama can exist, let alone local operas.

Houhe Drama is widespread in Puhua Houhe area in the ancient town of Zhuoshui, which locates in the Qianjiang District of Chongqing. So it is called the "Houhe Drama”. Today, Zhuoshui has lost its position as the important commerce center, but it has become an important tourist city in the Southeast of Chongqing. The prosperity of the tourism industry relies not only on material resources, but also on cultural resources. Therefore, Houhe Drama, as the important cultural symbol in tourism industry, has important status that cannot be ignored. The cultural name card of Houhe Drama should be full used to build the tourism market in the southeast of Chongqing. Combined with the current market situation, following measures can be used.

Creating and acting drama works which can reflect the minority culture in the southeast of Chongqing. Minorities have lived in this area for a long time. These remote and poor villages are less affected by various cultural waves, and remain the distinctive national characteristics. Subjects like Tusi, Bandits, Nuo opera and Tunpu can be used in Houhe Drama to create national dramas with regional characteristics, and to promote the historical and regional cultures in the southeast of Chongqing. A unique tourism brand can be created in that way.

Actively investing in the construction of national, custom and ecological museums. These museums can help people to inherit custom cultures, including dramas; they can also make intangible cultural heritages become sustainable tourism projects. Thus, merchants can obtain long-term economic benefits.

Actively investing an intangible cultural heritage base from the southeast area of Chongqing to Wujiang River Valley. Perfecting cultural arts like Wulong Impression Show, Xiushan Festival Lantern and Manghao Trumpet of Tujia, improving regional tourism services, and forming a cultural industry group with performing arts, crafts, tourism and local foods. Local operas like Houhe Opera can be developed in that base. Local characteristics should be created, and minority cultural brands with strong competitiveness should be introduced.

Traditional local operas like Houhe Opera are forms of intangible culture. They have unique historical and cultural values, as well as practical significance. The government and related departments, together with cultural workers, should actively think and take effective measures to prevent the extinction of traditional ethnic cultures. Various departments and local residents decide whether these traditional local operas can be properly preserved and inherited. Every units and individuals should try their best to preserve these Chinese cultural heritages.

\section{References:}

[1] Chinese opera: tunes and genres of traditional operas, in: General Editorial Board (Eds.), 
Encyclopedia of New China, Encyclopedia of China Publishing House, Beijing. 9 (2002) 587.

[2] R.A. Yang, Cultural anthropological investigation of Houhe Opera in the area of Qianjiang River, J. Sichuan Drama. 3 (2013) 36-39.

[3] X.G. Chen, Address on the 2003-2004 Annul Conference for Applying National Excellent Stage Art Projects, J. Art Express. 10 (2003) 6-7. 